ScIDice

\section{Effects Of Black Tea And Coffee On The Colour Stability Of Glass Ionomer Cement - An In Vitro Study}

Research Article

Kaviyaselvi Gurumurthy ${ }^{1}$, Balaji Ganesh $\mathrm{S}^{2 *}$, S Jayalakshmi ${ }^{3}$, Sasidharan $\mathrm{S}^{4}$

${ }^{1}$ Saveetha Dental College and Hospitals, Saveetha Institute of Medical and Technical Sciences (SIMATS), Saveetha University, Chennai- 77, India. ${ }^{2}$ Senior Lecturer, White Lab- Material Research Centre, Saveetha Dental College and Hospitals, Saveetha Institute of Medical and Technical Sciences [SIMATS], Saveetha University, Chennai- 77, India.

${ }^{3}$ Reader, White Lab- Material Research Centre, Saveetha Dental College and Hospitals, Saveetha Institute of Medical and Technical Sciences [SIMATS], Saveetha University, Chennai- 77, India.

${ }^{4}$ Tutor, White Lab- Material Research Centre, Saveetha Dental College and Hospitals, Saveetha Institute of Medical and Technical Sciences [SIMATS], Saveetha University, Chennai- 77, India.

\title{
Abstract
}

Background: Glass ionomer cements are restorative materials which bind to the surface of the tooth and additionally act as filling materials. The colour of the GIC chosen is subjective to the colour of the tooth. The colour stabilising property refers to the ability of the restorative material to maintain colour irrespective of the environmental changes. GIC also has the ability to resist discoloration when exposed to various liquids in the oral cavity. The aim of the present study was to determine the effects of black tea and black coffee on the colour stabilising property of different commercially available glass ionomer cements.

Materials and Method: Two commercially available GIC brands - shofu and D-tech, were chosen to test the colour stability of GIC. The GIC pellets were immersed in black tea, black coffee and distilled water for three days and the values from the spectrophotometer were recorded and analysed pre and post immersion.

Results: On performing the paired independent sample t test for the different glass ionomer cements used, Shofu brand of glass ionomer cement had low delta $\mathrm{E}$ values. The $\mathrm{p}$ value was found to be 0.036 for samples immersed in the beverages and the control. It was statistically significant.

Conclusion: The present study concluded that the Shofu brand of glass ionomer cement has the highest colour stability, due to their low delta E values. GIC samples stained with black tea were least color stable.

Keywords: Glass Ionomer Cements; Discolouration; Spectrophotometer; Color Stability; Innovative Technology.

\section{Introduction}

Restoration refers to any process which helps in re-establishing the normal morphology, function and integrity of the damaged tooth. The most customary dental restorative material used is glass ionomer cement (GIC) [1]. The reaction of calcium alumino fluorosilicate glass with an ionomer acts as the basis for the formation of glass ionomer cements. The components of a glass ionomer cement primarily consist of an acid, a base and a medium which is predominantly water [2]. These components along with its micromechanical strength help in adhesion of the glass ionomer cement to bond to the tooth surface. In addition, GICs help in restoration of primary teeth, act as liners and bases and act as a retrograde filling material. Further, GICs also help in prevention of dental caries due to its fluoride releasing property. The widespread use of glass ionomer comments in dentistry has led to the classification of GICs into four major groups which are used for luting crowns and bridges, aesthetic restorative cements, reinforced restorative cements and lining cements and base respectively. These glass ionomer cements differ with respect to their powder-liquid ratio but were similar in composition. Despite the advantages put forth, GICs lacked resistance to abrasion, sensitivity towards moisture and strength [3]. The glass ionomer cements used for pediatric procedures vary in implementation and me-

\section{*Corresponding Author:}

Dr. Balaji Ganesh S,

Senior Lecturer, White Lab- Material Research Centre, Saveetha Dental College and Hospitals, Saveetha Institute of Medical and Technical Sciences [SIMATS], Saveetha University, Chennai- 77, Tamil Nadu, India.

E-mail: balajiganeshs.sdc@saveetha.com

Received: September 13, 2021

Accepted: September 23, 2021

Published: September 24, 2021

Citation: Kaviyaselvi Gurumurthy, Balaji Ganesh S, S Jayalakshmi, Sasidharan S. Effects Of Black Tea And Coffee On The Colour Stability Of Glass Ionomer Cement - An In Vitro Study. Int J Dentistry Oral Sci. 2021;8(9):4642-4647. doi: http://dx.doi.org/10.19070/2377-8075-21000946

Copyright: Dr. Balaji Ganesh S ${ }^{\circ}$ 2021. This is an open-access article distributed under the terms of the Creative Commons Attribution License, which permits unrestricted use, distribution and reproduction in any medium, provided the original author and source are credited. 
chanical properties as compared to those employed for advanced dental procedures.

Colour stability is defined as the ability of any material to maintain its colour with time. Glass ionomer cements in general adopt the colour of the tooth and hence are aesthetically more appealing than other restorative materials [4]. However, with time the colour of dental restorative materials including GIC vary. This variation is directly proportional to the concentration and duration of exposure to factors which affect the colour of glass ionomer cement. The fluoride releasing property of GIC indirectly affects the colour stability of this restorative material. Addition of resin components to glass ionomer cement decreases the hardening time for GIC but increases the physical strengths and resistance to wearing [5].

Resin modified glass ionomer cements are known to undergo change in colour and this property is attributed to the photo polymerisation of the resin present, during the decelerated acid-base reaction. Based on the number of photons absorbed by the glass ionomer cements, the values are determined by a spectrophotometer [6]. Encapsulated glass ionomer restorative cements have been introduced whose physical properties surpass conventional glass ionomer cements [7]. The colour of restorative materials, in particular GIC, tends to vary with the type of liquids and solids consumed by the patient. The acidic nature of soft drinks, excess consumption of caffeine can indirectly alter the colour of glass ionomer cements but however vary with the initial time and duration of exposure. The present study was adopted to determine the effect of different beverages such as black coffee and black tea on the colour stability property of two different brands of glass ionomer cements.

\section{Materials and Methods}

To analyse the colour stability of glass ionomer cements, two different brands of commercially available glass ionomer cements (D-Tech and Shofu) were chosen. (Figure 1) The glass ionomer cements were purchased from an online dental store and processed and moulded into pellets of diameter $2 \mathrm{~mm}$. The pellets were trimmed and polished using a micrometer fixed with a fine polishing bur. The GIC pellets were then labelled numerically and those numbered 1, 2 were immersed in black coffee, 3 and 4 in black tea and 5, 6 in distilled water for each brand. Color stability was checked using Vita EasyShade Spectrophotometer.(Figure 2). The values from the spectrophotometer were noted and the GIC samples were soaked in black coffee, black tea and distilled water. The values from the spectrophotometer were recorded after immersion for 3 days at room temperature and compared.

\section{Results}

Table. 1 indicates the 'L', 'A' and 'B' spectrophotometer values of six samples of $\mathrm{d}$ Tech brand of glass ionomer cements prior to immersion in black tea and black coffee. ' $\mathrm{L}$ ' indicates the lightness of the sample, 'A' indicates the coordinates for red or green colour while ' $\mathrm{B}$ ' represents the coordinates for yellow or blue colour. From Table. 2, the pre immersion 'L', 'A' and 'B' values of the Shofu brand of glass ionomer cements are obtained. Table. 3 and Table. 4 represent the post immersion values ' $\mathrm{L}$ ', 'A' and 'B' values for $\mathrm{d}$ Tech and Shofu brands of glass ionomer cements respectively. The delta $\mathrm{E}$ values of the individual samples of $\mathrm{D}$ - tech and Shofu brand of glass ionomer cements are indicated in tables 5 and 6. Samples 1 and 2 were immersed in black coffee, samples 3 and 4 were immersed in black tea while samples 5 and 6 were immersed in distilled water (control) for both $\mathrm{d}$ Tech and shofu

Figure 1. The picture represents the sample of two different commercially available glass ionomer cements- D-Tech and Shofu respectively post immersion. Samples numbered 1 and 2 were immersed in black coffee, 3 and 4 were immersed in black tea and 5 and 6 were immersed in distilled water.

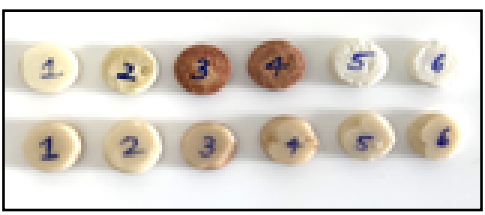

Figure 2. The recording of L,A,B values of each sample pre and post immersion in black tea and black coffee using VITA easyshade spectrophotometer.

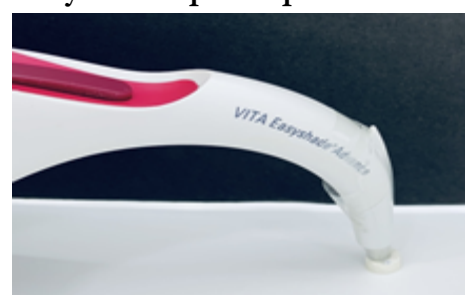

Table 1. Table representing the pre-immersion spectrophotometer values of $\mathrm{d}$-Tech GIC samples.

\begin{tabular}{|c|c|c|c|}
\hline S. No & L value & A value & B value \\
\hline 1. & 80 & 3 & 27 \\
\hline 2. & 85.8 & 1.6 & 31.9 \\
\hline 3. & 77.9 & 3.5 & 29.9 \\
\hline 4. & 78.9 & 3.6 & 32.2 \\
\hline 5. & 72.6 & 3.5 & 27.2 \\
\hline 6. & 80.1 & 2.8 & 29.5 \\
\hline
\end{tabular}


Table 2. Table representing the pre-immersion spectrophotometer values of Shofu GIC samples.

\begin{tabular}{|c|c|c|c|}
\hline S.No & L value & A value & B value \\
\hline 1. & 76.2 & 8.4 & 30.5 \\
\hline 2. & 82.5 & 6.7 & 27.5 \\
\hline 3. & 76.4 & 7.2 & 27.6 \\
\hline 4. & 76.7 & 8.8 & 31.7 \\
\hline 5. & 80.3 & 7 & 28.7 \\
\hline 6. & 83.6 & 6.7 & 28.3 \\
\hline
\end{tabular}

Table 3. Table representing the post immersion spectrophotometer values of D-Tech GIC samples.

\begin{tabular}{|c|c|c|c|}
\hline S.No & L value & A value & B value \\
\hline 1 & 74.4 & 2.3 & 24.1 \\
\hline 2 & 76.5 & 3.4 & 28.6 \\
\hline 3 & 49.86 & 6.43 & 26.43 \\
\hline 4 & 50.5 & 18.8 & 18.6 \\
\hline 5 & 79 & 1.6 & 23.4 \\
\hline 6 & 77.9 & 1.3 & 19.5 \\
\hline
\end{tabular}

Table 4. Table representing the post immersion spectrophotometer values of Shofu GIC samples.

\begin{tabular}{|c|c|c|c|}
\hline S.No & L value & A value & B value \\
\hline 1 & 75 & 7.9 & 27.6 \\
\hline 2 & 81.2 & 6.8 & 26.8 \\
\hline 3 & 62.5 & 17 & 23.1 \\
\hline 4 & 63.2 & 16.6 & 28 \\
\hline 5 & 80.1 & 6.7 & 24.6 \\
\hline 6 & 81.7 & 6.4 & 23.5 \\
\hline
\end{tabular}

Table 5. Table representing the delta $E$ values of D-Tech brand of GIC.

\begin{tabular}{|c|c|}
\hline S. No & Delta E value \\
\hline 1 & 6.345 \\
\hline 2 & 10.031 \\
\hline 3 & 28.405 \\
\hline 4 & 34.965 \\
\hline 5 & 7.682 \\
\hline 6 & 10.348 \\
\hline
\end{tabular}

Table 6. Table representing the delta E values of Shofu brand of GIC.

\begin{tabular}{|c|c|}
\hline S. No & Delta E value \\
\hline 1 & 3.178 \\
\hline 2 & 1.480 \\
\hline 3 & 17.593 \\
\hline 4 & 16.024 \\
\hline 5 & 4.116 \\
\hline 6 & 5.171 \\
\hline
\end{tabular}

Table 7. Table representing the mean delta $E$ values of D-Tech and Shofu GIC samples.

\begin{tabular}{|c|c|c|c|}
\hline Sample & Black Coffee & Black tea & Control \\
\hline D-Tech & 8.18 & 34.96 & 9.01 \\
\hline Shofu & 2.32 & 16.8 & 4.5 \\
\hline
\end{tabular}


Table 8. Table representing the mean and standard deviation values of colour stability between D-tech and Shofu.

\begin{tabular}{|c|c|c|c|c|c|}
\hline GROUPS & & $\mathbf{N}$ & MEAN & STANDARD DEVIATION & SIGNIFICANCE \\
\hline \multirow{2}{*}{ Delta E } & D-Tech & 5 & 17.486 & 13.234 & \multirow{2}{*}{0.036} \\
\cline { 2 - 5 } & Shofu & 5 & 8.478 & 7.683 & \\
\hline
\end{tabular}

Independent sample t test was used to find the significance. P value less than 0.05 was considered to be significant.

Figure 3. Bar graph showing the comparison of mean delta $E$ values and the samples of glass ionomer cements taken (D Tech and Shofu). $\mathrm{X}$ axis represents the different brands of glass ionomer cements while $\mathrm{Y}$ axis represents the mean delta $E$ values of the samples. Blue colour represents the Shofu brand of glass ionomer cement while the red colour represents the D-tech brand. The $\mathrm{p}$ value was found to be $\mathbf{0 . 0 3 6}$ for $\mathrm{D}$ Tech and shofu. $\mathrm{p}<0.05$ indicating statistically significant. From the graph, we can conclude that the Shofu brand of glass ionomer cement has the highest colour stability, due to their low mean delta $E$ values. GIC samples stained with black tea were least color stable.

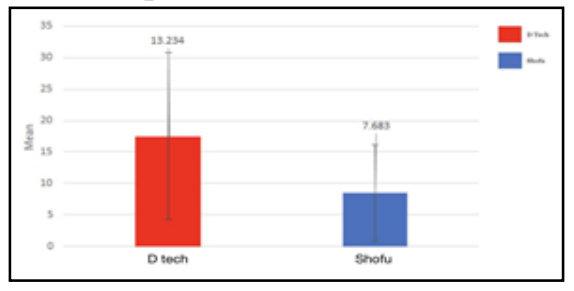

brands of glass ionomer cements. The mean delta $\mathrm{E}$ values of Shofu and d Tech brands of glass ionomer cements upon immersion in black coffee, black tea and distilled water are represented in Table. 7. On performing the independent sample $t$ test for the different glass ionomer cements used, the respective mean and standard deviations for delta $E$ values were compared as seen in Table.8. The $\mathrm{p}$ value was found to be 0.036 for $\mathrm{D}$ Tech and shofu. $\mathrm{p}<0.05$ indicating statistically significant. From the graph, we can conclude that the Shofu brand of glass ionomer cement has the highest colour stability, due to their low mean delta E values. GIC samples stained with black tea were least color stable (Figure 3).

\section{Discussion}

On analysing the results obtained from the present study, it was found that the glass ionomer cements immersed in black tea showed maximum variation in colour as compared to those immersed in black coffee and distilled water. The average delta $\mathrm{E}$ values for the D-Tech glass ionomer cement was found to be 8.18 and 34.96 while the Sofu brand had an average of 2.32 and 16.80 for black coffee and black tea respectively. On comparing these delta E values, it was noted that the colour variation in the D-Tech brand was more significant as compared to the Shofu brand owing to its high delta $\mathrm{E}$ value. The $\mathrm{p}$ value was found to be 0.036 $(p<0.05)$ for the samples immersed in both the beverages and the control group, indicating statistically significant values. The samples immersed in distilled water acted as the control as their delta $E$ values remained a constant for the entire duration of the experiment. Further, the Shofu brand immersed in black coffee had the least change in colour when morphologically assessed. GIC samples stained with black tea were least color stable.

Colour stability, commonly known as chromatic stability, refers to the ability of any restorative material to resist a change in its colour on exposure to various substances and chemicals. Based on the duration of exposure and the substance involved, the colour change can be extrinsic in nature, a subsurface alteration or intrinsic discolouration [8]. The colour stabilising property of the restorative material is essential in determining the success of the restorative procedure in the long run. To test this property, various visual and instrumental methods have been developed, the most common one being spectrophotometric analysis [9]. This test determines the intensity of wavelength absorbed when light rays pass through the restorative material. Certain restorative materials tend to undergo a change in their physical properties and softening parallel to the colour change [10].

Based on a study conducted by Dalia Mohamed et al, it was stated that there was no significant difference in colour between glass ionomer cements immersed in coffee and distilled water. However, the change in colour of the cements varied with the duration of immersion. The change in colour was found to be maximum between the 7th and 30th days of immersion. On comparing the delta $E$ values obtained for glass ionomer cements immersed in coffee and tea, it was noted that the values were higher for immersion in tea and thus the cements immersed in the same had the least colour stability which are in accordance with the results obtained from the present study [11].

In order to enhance the physical and mechanical properties of restorative materials, certain modifications in their composition are brought about, some of which include addition of metals, resins and nanoparticles [12]. In the research conducted by A.R. Prabhakar et al, it was observed that conventional glass ionomer cements were better resisted to change in colour as compared to resin modified glass ionomer cements, upon treatment with chlorhexidine. Further, the fluoride releasing capacity also varied inversely with the colour stability due to the higher dissolution of the surface of the restorative material. Thus, resin modified glass ionomer cements portrayed an increased release of fluoride ions [13].

The use of glass ionomer cements for various dental procedures has become increasingly popular due to their restorative property, fluoride releasing capacity and physical strength. The most essential factor which is considered when a restorative material is chosen, is its ability to match the colour of the tooth, the texture and roughness [14]. Based on previous studies, glass ionomer 
cements were known to possess less colour stability due to the presence of polyacidic substances in their composition. In certain modifications of GIC such as resin modified glass ionomer cements, the colour stability is decreased due to the From the article proposed by Yadav Chakravarthy, it was noted that the GICs produced maximum change in colour after immersion in red wine due to the high concentration of phenolic compounds [15]. On immersion in fruit juices, the colour of glass ionomer cements varied considerably in acidic juices as compared to alkaline and basic fruit juices. The $\mathrm{pH}$ of these juices could potentiate the release of hydrogen ions and facilitate erosion thereby comprising the colour of the glass ionomer cement. Irrespective of the duration of immersion, GIC produces discolouration and their ability to absorb water from the immersion medium aid in this process. Upon reaching saturation and stability, the change in colour is inhibited and the change in mechanical properties cease [16].

Our team has extensive knowledge and research experience that has translated into high quality publications [17-36]. The present study however possesses certain limitations due to its limited sample size and restriction to only two brands of GIC. In the future, the color stability of nanoparticles with added glass ionomer cements can be studied.

\section{Conclusion}

The present study concluded that the Shofu brand of glass ionomer cement has the highest colour stability, due to their low delta $E$ values. GIC samples stained with black tea were least color stable.

\section{Acknowledgement}

We thank Saveetha Dental College and Hospitals for providing us the support to conduct the study.

\section{Funding}

The present study is funded by the following

- Saveetha Dental College and Hospitals, Saveetha Institute of Medical and Technical Sciences, Saveetha University, Chennai

- Sarkav Health Services

\section{References}

[1]. Strub JR, Rekow ED, Witkowski S. Computer-aided design and fabrication of dental restorations: current systems and future possibilities. J Am Dent Assoc. 2006 Sep;137(9):1289-96.Pubmed PMID: 16946436.

[2]. Gu YW, Yap AU, Cheang P, Khor KA. Effects of incorporation of $\mathrm{HA} / \mathrm{ZrO}(2)$ into glass ionomer cement (GIC). Biomaterials. 2005 Mar;26(7):713-20. Pubmed PMID: 15350775

[3]. Moshaverinia A, Ansari S, Moshaverinia M, Roohpour N, Darr JA, Rehman I. Effects of incorporation of hydroxyapatite and fluoroapatite nanobioceramics into conventional glass ionomer cements (GIC). Acta Biomater. 2008 Mar;4(2):432-40.Pubmed PMID: 17921077.

[4]. Bhattacharya S, Purayil TP, Ginjupalli K, Kini S, Pai S. Effect of thermocycling on the colour stability of aesthetic restorative materials: An in-vitro spectrophotometric analysis. Pesqui Bras Odontopediatria Clin Integr. 2020;20.

[5]. Ahmad I, Iqbal K, Ahmed S, Sheraz MA, Aminuddin M. Applications of laser flash photolysis, spectroscopy and electron microscopy in photopolymerization and development of glass ionomer dental cements. J. Mater. Sci. Res. 2011;5(1):1-21.
[6]. Adusumilli H, Avula JS, Kakarla P, Bandi S, Mallela GM, Vallabhaneni K. Color stability of esthetic restorative materials used in pediatric dentistry: An in vitro study. J Indian Soc Pedod Prev Dent. 2016 Jul 1;34(3):233-7.

[7]. Al-Taee L, Deb S, Banerjee A. An in vitro assessment of the physical properties of manually- mixed and encapsulated glass-ionomer cements. BDJ Open. 2020 Aug 11;6:12.Pubmed PMID: 32821430.

[8]. Samra AP, Pereira SK, Delgado LC, Borges CP. Color stability evaluation of aesthetic restorative materials. Braz Oral Res. 2008 Sep;22(3):205-10.

[9]. Cal E, Güneri P, Kose T. Comparison of digital and spectrophotometric measurements of colour shade guides. J Oral Rehabil. 2006 Mar;33(3):2218.

[10]. Dayan C, Guven MC, Gencel B, Bural C. A Comparison of the Color Stability of Conventional and CAD/CAM Polymethyl Methacrylate Denture Base Materials. Acta Stomatol Croat. 2019 Jun;53(2):158-167.Pubmed PMID: 31341324.

[11]. Hamid DM, Mahmoud GM, El-Sharkawy FM, Abou Auf EA. Effect of surface protection, staining beverages and aging on the color stability and hardness of recently introduced uncoated glass ionomer restorative material. Futur. Dent. J. 2018 Dec 1;4(2):288-96.

[12]. Pani SC, Aljammaz MT, Alrugi AM, Aljumaah AM, Alkahtani YM, AlKhuraif A. Color Stability of Glass Ionomer Cement after Reinforced with Two Different Nanoparticles. Int J Dent. 2020 May 31;2020:7808535. Pubmed PMID: 32565811.

[13]. Prabhakar A, Pattanshetti K, Sugandhan S. A comparative study of color stability and fluoride release from glass ionomer cements combined with chlorhexidine. Int J Clin Pediatr Dent. 2013 Jan;6(1):26-9.Pubmed PMID: 25206183.

[14]. Kleverlaan CJ, van Duinen RN, Feilzer AJ. Mechanical properties of glass ionomer cements affected by curing methods. Dent Mater. 2004 Jan $1 ; 20(1): 45-50$.

[15]. Chakravarthy Y, Clarence S. The effect of red wine on colour stability of three different types of esthetic restorative materials: An in vitro study. J Conserv Dent. 2018 May-Jun;21(3):319-323.Pubmed PMID: 29899637.

[16]. Biancalana RC, Freitas Vincenti SA, Alves da Silva RH, Carvalho Panzeri Pires-de-Souza F. Color stability of dental restorative materials submitted to cold temperatures for forensic purposes. J Forensic Leg Med. 2017 Oct;51:63-68.Pubmed PMID: 28759777.

[17]. Muthukrishnan L. Imminent antimicrobial bioink deploying cellulose, alginate, EPS and synthetic polymers for 3D bioprinting of tissue constructs. Carbohydr Polym. 2021 May 15;260:117774.Pubmed PMID: 33712131.

[18]. PradeepKumar AR, Shemesh H, Nivedhitha MS, Hashir MMJ, Arockiam S, Uma Maheswari TN, et al. Diagnosis of Vertical Root Fractures by Conebeam Computed Tomography in Root-filled Teeth with Confirmation by Direct Visualization: A Systematic Review and Meta-Analysis. J Endod. 2021 Aug;47(8):1198-1214.Pubmed PMID: 33984375.

[19]. Chakraborty T, Jamal RF, Battineni G, Teja KV, Marto CM, Spagnuolo G. A Review of Prolonged Post-COVID-19 Symptoms and Their Implications on Dental Management. Int J Environ Res Public Health. 2021 May 12;18(10):5131.Pubmed PMID: 34066174.

[20]. Muthukrishnan L. Nanotechnology for cleaner leather production: a review. Environ Chem Lett. 2021 Jan 13;19(3):2527-49.

[21]. Teja KV, Ramesh S. Is a filled lateral canal - A sign of superiority? J Dent Sci. 2020 Dec;15(4):562-563.Pubmed PMID: 33505634.

[22]. Narendran K, MS N, SARVANAN A, SUKUMAR E. Synthesis, Characterization, Free Radical Scavenging and Cytotoxic Activities of Phenylvilangin, a Substituted Dimer of Embelin. ijps. 2020 Sep 1;82(5).

[23]. Reddy P, Krithikadatta J, Srinivasan V, Raghu S, Velumurugan N. Dental Caries Profile and Associated Risk Factors Among Adolescent School Children in an Urban South-Indian City. Oral Health Prev Dent. 2020 Apr 1;18(1):379-386.Pubmed PMID: 32618460.

[24]. Sawant K, Pawar AM, Banga KS, Machado R, Karobari MI, Marya A, et al. Dentinal Microcracks after Root Canal Instrumentation Using Instruments Manufactured with Different NiTi Alloys and the SAF System: A Systematic Review. Appl. Sci. 2021 Jan;11(11):4984.

[25]. Bhavikatti SK, Karobari MI, Zainuddin SLA, Marya A, Nadaf SJ, Sawant VJ, et al. Investigating the Antioxidant and Cytocompatibility of Mimusops elengi Linn Extract over Human Gingival Fibroblast Cells. Int J Environ Res Public Health. 2021 Jul 4;18(13):7162.Pubmed PMID: 34281099.

[26]. Karobari MI, Basheer SN, Sayed FR, Shaikh S, Agwan MAS, Marya A, et al. An In Vitro Stereomicroscopic Evaluation of Bioactivity between Neo MTA Plus, Pro Root MTA, BIODENTINE \& Glass Ionomer Cement Using Dye Penetration Method. Materials (Basel). 2021 Jun 8;14(12):3159.Pubmed PMID: 34201321

[27]. Rohit Singh T, Ezhilarasan D. Ethanolic extract of Lagerstroemia Speciosa (L.) Pers., induces apoptosis and cell cycle arrest in HepG2 cells. Nutr Cancer. 2020 Jan 2;72(1):146-56.

[28]. Ezhilarasan D. MicroRNA interplay between hepatic stellate cell quiescence 
and activation. Eur J Pharmacol. 2020 Oct 15;885:173507.Pubmed PMID: 32858048

[29]. Romera A, Peredpaya S, Shparyk Y, Bondarenko I, Bariani GM, Abdalla $\mathrm{KC}$, et al. Bevacizumab biosimilar BEVZ92 versus reference bevacizumab in combination with FOLFOX or FOLFIRI as first-line treatment for metastatic colorectal cancer: a multicentre, open-label, randomised controlled trial. Lancet Gastroenterol Hepatol. 2018 Dec 1;3(12):845-55.

[30]. Raj R K, D E, S R. 囚-Sitosterol-assisted silver nanoparticles activates Nrf2 and triggers mitochondrial apoptosis via oxidative stress in human hepatocellular cancer cell line. J Biomed Mater Res A. 2020 Sep;108(9):18991908.Pubmed PMID: 32319188.

[31]. Vijayashree Priyadharsini J. In silico validation of the non-antibiotic drugs acetaminophen and ibuprofen as antibacterial agents against red complex pathogens. J Periodontol. 2019 Dec;90(12):1441-1448.Pubmed PMID: 31257588 .

[32]. Priyadharsini JV, Girija AS, Paramasivam A. In silico analysis of virulence genes in an emerging dental pathogen A. baumannii and related species.
Arch. Oral Biol. 2018 Oct 1;94:93-8.

[33]. Uma Maheswari TN, Nivedhitha MS, Ramani P. Expression profile of salivary micro RNA-21 and 31 in oral potentially malignant disorders. Braz Oral Res. 2020 Feb 10;34:e002.Pubmed PMID: 32049107.

[34]. Gudipaneni RK, Alam MK, Patil SR, Karobari MI. Measurement of the Maximum Occlusal Bite Force and its Relation to the Caries Spectrum of First Permanent Molars in Early Permanent Dentition. J Clin Pediatr Dent. 2020 Dec 1;44(6):423-428.Pubmed PMID: 33378468.

[35]. Chaturvedula BB, Muthukrishnan A, Bhuvaraghan A, Sandler J, Thiruvenkatachari B. Dens invaginatus: a review and orthodontic implications. $\mathrm{Br}$ Dent J. 2021 Mar;230(6):345-350.Pubmed PMID: 33772187.

[36]. Kanniah P, Radhamani J, Chelliah P, Muthusamy N, Joshua Jebasingh Sathiya Balasingh Thangapandi E, Reeta Thangapandi J, et al. Green synthesis of multifaceted silver nanoparticles using the flower extract of Aerva lanata and evaluation of its biological and environmental applications. ChemistrySelect. 2020 Feb 21;5(7):2322-31. 